Article

\title{
A Simple and Reasonable Calculation Equation of Balanced Fertilization
}

\section{Shenwu Lv ${ }^{1}$, Xuemei Wang ${ }^{2}$ and Gangcai Liu ${ }^{2, *}$}

1 Agricultural Bureau of Sichuan, Nanchong Gaoping District, Nanchong 637100, China; E-Mail: chaq163@163.com

2 Key Laboratory of Mountain Hazards and Earth Surface Processes, Institute of Mountain Hazards and Environment, Chinese Academy of Sciences and Ministry of Water Resources, Chengdu 610041, China; E-Mail: liugc@imde.ac.cn

* Author to whom correspondence should be addressed; E-Mail: liugc@imde.ac.cn; Tel./Fax:: +86-28-8523-1287.

Academic Editor: Mariangela Diacono

Received: 17 March 2015 / Accepted: 20 May 2015 / Published: 25 May 2015

\begin{abstract}
Reasonable fertilization is a primary concern for agronomy scientists and farmers. However, there is still no satisfying calculation formula to guide farmer's fertilizing. Five kinds of indices were tested in more than 500 field plots successively, and more than 50 pieces of long-term and short-term fertilizer field test data acquired by others were analyzed. Quick-acting fertilizers should be applied for balanced fertilization if the soil-available nutrient content is within the normal range. Through rigorous derivation and validation by a multi-year continuous ${ }^{15} \mathrm{~N}$ tracer field test, it is obtained that, total soil exogenous $\mathrm{N}=$ total output $\mathrm{N}$ - total recovery $\mathrm{N}+$ soil profit or lost $\mathrm{N}$; utilization efficiency of fertilizer $\mathrm{N}=$ (output $\mathrm{N}-$ exogenous $\mathrm{N}) \div$ balanced application amount of $\mathrm{N}$ fertilizer. Optimal balanced utilization efficiency of fertilizer $\mathrm{N}, \mathrm{P}, \mathrm{K}=$ total recovery efficiency, and soil nutrient net amount $=$ total amount after test - total amount before test. Equation application parameters were collected from more than 50 tests, which is more applicable than collecting from a single test. When soil-available nutrient content is excessively low or excessively high, adjusting this should be based on balanced fertilization to properly increase or reduce the fertilization rate.
\end{abstract}

Keywords: fertilizer utilization; fertilizer requirement; soil nutrient balance account 


\section{Introduction}

All domestic and foreign calculation equations of farmland fertilization are flawed. The soil fertility dissimilar subtraction method [1] has a base of higher CK with underestimated seasonal fertilizer utilization. The ${ }^{15} \mathrm{~N}$ tracer method is very good, but the absorptivity in the initial season used to represent the utilization is also quite low [2,3], and thus unable to reflect the real use of fertilizer. The measurement method of fertilizer application in the fertilizer effect function was put forward by the United Nations Food and Agriculture Organization (FAO) in 1976 and can achieve the optimal economic benefit, but long-term excessive fertilization results in poor ecological environmental benefit [4,5]. Since 1980, many farmers have been used to apply fertilizer in amounts that nearly cause crop lodging in China, resulting in more $\mathrm{N}$ and $\mathrm{P}$ fertilization - potentially up to $20 \%-100 \%[6,7]$. After two decades, $\mathrm{N}$ and $\mathrm{P}$ contents of most soils have improved greatly [6,8], and soil-available $\mathrm{N}$ and $\mathrm{P}$ contents are exorbitant, leading to crop output reduction [9] and environmental and health problems in many regions [10,11]. After 1968, testing soil regarding fertilization has been carried out in the United States [12,13]. Combined with the soil nutrient abundance and deficiency index, it is common that soil with high fertility needs no fertilization, soil with "medium" fertility needs suitable fertilization and soil with "low" fertility needs a lot of fertilization [14-16]. This method has certain applicability, but how to allocate, realize and calculate a reasonable amount is a core problem to be discussed in this study.

\section{Main complete Set Calculation Equation of the Balanced Fertilization Method}

The main complete set calculation equation of balanced fertilization has been published in domestic journals after rigorous derivation and validation [17-20], introduced as follows. The non-harvested plant root system is not able to carry nutrients out, thus the nutrient absorption are excluded from that of root system in this study, and root nutrients are included in the residue. After the long-term field near-balance fertilization test by the ${ }^{15} \mathrm{~N}$ tracer, the following equation has been deduced:

Total soil exogenous $\mathrm{N}=$ Total output $\mathrm{N}-$ Total recovery $\mathrm{N}+$ Soil profit or lost $\mathrm{N}$

In this study, exogenous $\mathrm{N}$ includes biological nitrogen fixation. The $\mathrm{N}$ is brought by the water from atmospheric dry and wet deposition quantities, irrigation and seedlings and the net income of exogenous $\mathrm{N}$ eliminates the loss of soil $\mathrm{N}$ [21].

\subsection{Fertilizer Utilization Rate}

Utilization rate of fertilizer $\mathrm{N}=($ fertilizer $\mathrm{N}+$ exchanged utilization $\mathrm{N}) \div$ applied fertilizer $\mathrm{N} \times$ $100 \%$. In the equation, the exchanged utilization $\mathrm{N}$ [22-24] refers to net exported soil $\mathrm{N}$ returned and compensated by fertilizer residual $\mathrm{N}$. Net exported soil $\mathrm{N}=$ exported soil $\mathrm{N}$ - exogenous $\mathrm{N}$. Exchanged utilization $\mathrm{N}$ usually refers to two cases: (a) When the fertilization is slightly less; net exported soil $\mathrm{N} \geq$ fertilizer residual $\mathrm{N}$, exchanged utilization $\mathrm{N}=$ fertilizer residual $\mathrm{N}$ and utilization rate of fertilizer $\mathrm{N}$ during the application season $=$ total recovery rate. The part from the net exported soil $\mathrm{N}$ minus residual $\mathrm{N}$ is the net exported mineralized soil $\mathrm{N}$, i.e., the part from the apparent utilization rate minus the total recovery rate; (b) When the fertilization is slightly higher, net exported soil $\mathrm{N} \leq$ fertilizer 
residual $\mathrm{N}$ and exchanged utilization $\mathrm{N}=$ net exported soil $\mathrm{N}$. Utilization rate of fertilizer $\mathrm{N}$ during the application season $=($ fertilizer $\mathrm{N}+$ soil $\mathrm{N}-$ exogenous $\mathrm{N}) \div$ applied fertilizer $\mathrm{N}=($ output $\mathrm{N}-$ exogenous $\mathrm{N}) \div$ applied fertilizer $\mathrm{N}$, thus:

Utilization rate of fertilizer $\mathrm{N}=($ output $\mathrm{N}-$ exogenous $\mathrm{N}) \div$ balanced application of fertilizer $\mathrm{N} \times 100 \%$

As viewed from condition (a) and (b), exchanged utilization $\mathrm{N} \leq$ residual $\mathrm{N}$, so that the utilization rate of fertilizer $\mathrm{N} \leq$ total recovery rate. In the long-term field dissimilar subtraction test, the utilization rate of fertilizer $\mathrm{N}$ during the application season will tend to the calculated value of Equation (2) [25] in the middle and later periods.

When a balanced application of readily available fertilizer is carried out, the utilization rate of fertilizer $\mathrm{N}=$ total recovery rate. When a homometric application of delayed available fertilizer is carried out, utilization rate of fertilizer $\mathrm{N}$ during the application season $<$ total recovery rate. Therefore, the experiment of fertilizer utilization rate must be conducted approaching the balanced fertilization conditions. When $\mathrm{C} / \mathrm{N}$ value $<10$ for balanced fertilizer application:

Balanced optimal utilization rate of fertilizer $\mathrm{N}, \mathrm{P}, \mathrm{K}=$ total recovery rate

In the long-term field non-tracer test, when approaching balanced fertilization, fertilizer utilization rate is close to total recovery rate:

Total recovery rate of $\mathrm{N}=$ (output $\mathrm{N}-$ exogenous $\mathrm{N}+$ profit or lost $\mathrm{N}) \div$ applied fertilizer $\mathrm{N} \times 100 \%$

Total recovery rate of $\mathrm{P}, \mathrm{K}=$ (output amount + profit or lost amount $) \div$ applied fertilizer amount $\times 100 \%$

The utilization rate of delayed available fertilizer during the application season with $25 \geq \mathrm{C} / \mathrm{N} \geq 10$ is less than total recovery rate at the beginning of application. In Equation (4), exogenous $\mathrm{N}$ has been offset; it can only be achieved by a continuous test of the annual input-output ratio of organic fertilizer to calculate the complementary fertilization amount. In order to shorten the test time, the fertilizer application test is carried out by combined half organic fertilizer $\mathrm{N}+$ half chemical fertilizer $\mathrm{N}$. The test continues until the year when the output in the combined fertilization area is close to that in the only chemical fertilizer application area, and then, the annual input-output ratio can be calculated.

The input-output ratio of combined applied fertilizer $\mathrm{N}, \mathrm{P}$ and $\mathrm{K}=$ output $\div$ combined fertilization amount

In Equation (6), the N, P, K amount of organic fertilizer or combined applied fertilizer is converted into output. When the output in the organic fertilizer area approaches that in the chemical fertilizer application area after continuous fertilizer application, the utilization rate during the application season can be the constant total recovery rate. The input-output ratio can be tested in lands with high, medium and low productivity.

For the utilization rate of organic fertilizer with $\mathrm{C} / \mathrm{N}>25$ during the applied season in delayed available fertilizer, especially for returning straw to fields, it is best to add fertilizer $\mathrm{N}$ and farm manure to straw so as to adjust $\mathrm{C} / \mathrm{N}$ to 25 or so; then, straw is heaped for composting at field boundaries for a season. 
Sixty percent chemical fertilizers and $40 \%$ straw composting with $\mathrm{N}$ nutrients are applied, and then, according to Equation (4), the complementary fertilization amount is calculated. For winter paddy fields with no water in winter, straw can be scattered in the fields for composting in the following season. Before cropping in the next season, the contents of soil-available nutrients must be determined and adjusted. Farm manure is commonly applied in farmlands and has been used for many years. The utilization rate of $\mathrm{N}, \mathrm{P}$ and $\mathrm{K}$ during the applied season is equal to the total recovery rate of the respective fertilizer.

\subsection{Reasonable Equation of Fertilization Amount}

When $\mathrm{C} / \mathrm{N}<10$ for fertilizer,

Balance fertilization $\mathrm{N}=($ target output $\mathrm{N}-$ exogenous $\mathrm{N}) \div$ total recovery rate of $\mathrm{N}$

During the homometric application of organic fertilizer or the combined application of fertilizer with $25 \geq \mathrm{C} / \mathrm{N} \geq 10$ or the application of delayed available fertilizer $\mathrm{P}$ and $\mathrm{K}$ is used, the fertilization amount is calculated as below:

Fertilizer N, $\mathrm{P}=$ (target output - output in the area with organic fertilizer application $) \div$ total recovery rate of fertilizer

During the application of readily available fertilizer $\mathrm{P}$ and $\mathrm{K}$,

$\mathrm{P}, \mathrm{K}$ requirement $=$ the content of target output $\div$ total recovery rate of fertilizer

\subsection{Net Residual Soil N}

Net residual $\mathrm{N}$ refers to the absolute net residue of fertilizer $\mathrm{N}$ in soil after income and expenses of soil $\mathrm{N}$ is offset, defined as soil profit or lost $\mathrm{N}$. Net residual $\mathrm{N}=$ residual $\mathrm{N}-$ net exported soil $\mathrm{N}=$ total recovery of $\mathrm{N}-$ fertilizer $\mathrm{N}-$ soil $\mathrm{N}+$ exogenous $\mathrm{N}=$ total recovery $\mathrm{N}-$ output $\mathrm{N}+$ exogenous $\mathrm{N}$. The right side of the latter equation is multiplied and divided by the applied fertilizer $\mathrm{N}$ to draw a simple measuring method:

Net residual $\mathrm{N}=($ total recovery rate - apparent utilization rate $) \times$ fertilization amount of

$\mathrm{N}=$ total soil $\mathrm{N}$ after test - total soil $\mathrm{N}$ before test

According to the total recovery rate of tested fertilizer $\mathrm{N}$ and soil exogenous $\mathrm{N}$ of each season as well as the farmland production situation of the previous season, Equation (10) can be used to easily adjust the seasonal fertilization close to the balanced optimal fertilization amount of $\mathrm{N}$ and $\mathrm{P}$. It is the net residue of fertilizer nutrients with substantive significance. These complete set equations of balanced fertilization are common for any climate, region, soil and plant for vegetation growth.

\section{Application Parameters of Reasonable Balanced Fertilization}

Since 1983, the Ministry of Agriculture has issued a soil nutrient abundance and deficiency index to test and carry out agricultural environment quality survey and monitoring. The Sichuan Provincial Agriculture Department has ordered the conduct of experiments to improve land efficiency, observe the soil erosion of slope croplands and conduct soil testing of land for fertilizing, etc. 


\subsection{Application Parameters of Complete Set Equation on the Balanced Application of Fertilizers $N$ and $P$}

Major soil species with different productivities were tested from 1985 to 1987 to grow wheat, corn and rice by reasonable fertilization and to observe the nutrient contents of grains and straws. In this county, winter water (leisure) rice crop rotation is carried out in single-cropping paddy fields. Through analyzing more than 50 short-term ${ }^{15} \mathrm{~N}$ tracer tests and long-term field fertilizer experiments carried out by others, the exogenous $\mathrm{N}$ and total nitrogen recovery rate of soil species with different productivities were estimated in this county. In order to avoid the smaller total recovery rate of fertilizer nutrients, two soil layers of $0-40 \mathrm{~cm}$ were generally measured in paddy fields while three soil layers of $0-60 \mathrm{~cm}$ were measured to obtain the residues and soil nutrient profit or lost in dry land because there are a lot of plant roots in these soil layers. Micro-zone borders should also be built solidly to avoid rainstorms washing micro-zone soil. In addition, according to runoff plot experiments, the loss rate of phosphate fertilizer was measured, shown in Table 1 [26]. Cropping was carried out in this regional arid land only twice, and annual exogenous $\mathrm{N}$ was distributed to two cropping seasons evenly. When soil-available nutrients are ranged in the normal contents as shown in Table 2, only Equations (2) and (7)-(9) can be used to calculate the balanced fertilizer application. The following is a calculation case: $\mathrm{N}_{5}$ represents stony soil, and the $\mathrm{N}$ requirement for wheat growth $=$ (output $\mathrm{N}-$ exogenous $\mathrm{N}) \div$ total recovery rate of $\mathrm{N}=(79.5-16) \div 0.62=102 \mathrm{kgN} / \mathrm{ha}$. The sunlight is relatively less in the Sichuan Basin than in other Chinese regions, and crop yields are also lower. The exogenous $\mathrm{N}$ is more in tropical soil, but more precipitation exists, leading to lower total fertilizer recovery rate, which is a partial offset for regional differences. According to regional crop yields, the calculated fertilizer requirement is more appropriate. At present, there is no accurate data on soil exogenous $\mathrm{N}$ and total fertilizer recovery rate in each climatic zone; thus, the data in this paper can be used for reference. However, more fertilizer nutrients are brought from settlements that self-fertilize their lands and this should be deducted from the fertilizer requirement.

Table 1. Estimates of fertilizer $\mathrm{N}$ application in soil with high/low output ( $\mathrm{kgN} / \mathrm{ha}, \%)$.

\begin{tabular}{cccccccc}
\hline Crop & Soil & Exogenous N & yield & Output N & $\begin{array}{c}\text { Total Recovery } \\
\text { rate of N }\end{array}$ & $\begin{array}{c}\text { N } \\
\text { Requirement }\end{array}$ & $\begin{array}{c}\text { Total Recovery rate } \\
\text { of P }\end{array}$ \\
\hline \multirow{6}{*}{ Wheat } & $\mathrm{N}_{1}$ & 26 & 4300 & 120.4 & 73 & 129 & 95 \\
& $\mathrm{~N}_{2}$ & 25 & 4105 & 114.9 & 72 & 125 & 94 \\
& $\mathrm{~N}_{3}$ & 23 & 3870 & 108.4 & 70 & 127 & 93 \\
& $\mathrm{~N}_{4}$ & 21 & 3430 & 96.0 & 67 & 114 & 92 \\
& $\mathrm{~N}_{5}$ & 16 & 2840 & 79.5 & 62 & 102 & 90 \\
\hline \multirow{6}{*}{ Corn } & $\mathrm{N}_{1}$ & 26 & 4800 & 115.2 & 72 & 124 & 94 \\
& $\mathrm{~N}_{2}$ & 25 & 4650 & 111.6 & 71 & 122 & 92 \\
& $\mathrm{~N}_{3}$ & 23 & 4400 & 105.6 & 70 & 118 & 91 \\
& $\mathrm{~N}_{4}$ & 21 & 3916 & 94 & 66 & 90 & 90 \\
\hline \multirow{6}{*}{ Rice } & $\mathrm{N}_{5}$ & 16 & 2944 & 70.7 & 61 & 111 & 93 \\
& $\mathrm{~N}_{6}$ & 56 & 8500 & 161.5 & 72 & 136 & 92 \\
& $\mathrm{~N}_{7}$ & 49 & 7500 & 142.5 & 69 & 129 & 90 \\
\hline
\end{tabular}


Table 2. Normal content range of available nutrients in soil of different kinds ( $\mathrm{mg} / \mathrm{kg})$.

\begin{tabular}{ccccccc}
\hline \multirow{2}{*}{ Available Nutrients } & \multicolumn{3}{c}{ Arid Land } & \multicolumn{3}{c}{ Paddy Land } \\
\cline { 2 - 7 } & Light Loam & Medium Loam & Heavy Loam & Light Loam & Medium Loam & Heavy Loam \\
\hline${ }^{1} \mathrm{~N}$ & $45-55$ & $55-65$ & $65-80$ & $50-65$ & $65-80$ & $80-100$ \\
${ }^{2} \mathrm{P}$ & $5-8$ & $6-10$ & $8-12$ & $6-9$ & $9-12$ & $12-15$ \\
${ }^{3} \mathrm{~K}$ & $50-60$ & $60-75$ & $75-95$ & $55-65$ & $65-80$ & $75-100$ \\
\hline
\end{tabular}

1 The diffusion-absorption method for available $\mathrm{N}$; ${ }^{2}$ sodium bicarbonate extraction and $\mathrm{Mo}-\mathrm{Sb}-\mathrm{Vc}$ colorimetry for available $\mathrm{P} ;{ }^{3}$ sodium tetraphenyl boron turbidimetry for available $\mathrm{K}$.

\subsection{Reasonable Fertilization Amounts for the Soils with Excessively High or Low Available Nutrients}

According to the conducted experiments of the soil nutrient abundance and deficiency index and soil testing for fertilization, as well as the second national soil census data in this county, the normal content range of soil-available nutrients in $0-20 \mathrm{~cm}$ of surface soil with different qualities are shown in Table 2. In the case of soil-available nutrients beyond normal levels, according to multi-year tests and the guiding experience of farmland production, it is initially determined that, in the lands with light loam, medium loam and heavy soil, if the contents of soil-available nutrients $\mathrm{N}, \mathrm{P}$ and $\mathrm{K}$ in the lands with different qualities are below the normal lower limit, for every $10 \%$, balanced fertilization will be increased by $15 \%$. If those of $\mathrm{N}$ and $\mathrm{P}$ are higher than the normal ceiling, for every $10 \%$, balanced fertilization will be reduced by $20 \%$, leading to a reasonable and practical application of $\mathrm{N}$ and $\mathrm{P}$ fertilizer in farmlands. For example, N5 represents gravelly medium loam; the balanced fertilization $\mathrm{N}$ is $102 \mathrm{kgN} / \mathrm{ha}$, and soil-available $\mathrm{N}$ content is $72 \mathrm{mgN} / \mathrm{kg}$, higher than the ceiling by $(72-65) \div 65=10.8 \%$. Reasonable fertilization $\mathrm{N}=102-102 \times 10.8 \% \times 2=80(\mathrm{kgN} / \mathrm{ha})$, which is feasible in production practice. When soil-available potassium content is in a normal range, except for potassium crops, not applying fertilizer $\mathrm{K}$ will not cut down the output. As fertilizer $\mathrm{K}$ is always lacking, only K-deficiency soil is applied with fertilizer K. In terms of fertilization method, all fertilizers should not be used as basal fertilization. Rice and wheat should be applied with basal fertilization and jointing fertilization; corn should be fertilized by basal fertilization, seedling fertilization and budding fertilization, which can increase the seasonal fertilizer absorption but reduce unnecessary residues. It is confirmed that crops grow in the seedling stage and normally turn yellow in the mature period. Less fertilizer nitrogen should be applied in the next cropping to stop crops turning yellow and maintain higher crop yields.

\section{Conclusions}

In conclusion, mathematical derivation has been conducted in accordance with objective laws so as to make a complete set calculation equation of farmland fertilization that is on the right track and to conclude the fertilizer utilization law in the current cropping, i.e., the balanced optimal utilization rate of available nutrients in the current cropping is equal to the total recovery rate of balanced fertilization. After continuous use of delayed available fertilizers, when the nutrient utilization in the current cropping is increased to be that of readily available fertilizer, it can also be used as constant total recovery rate. Its value is positively correlated to crop yield by balanced fertilization in the soil with different productivities. The promotion of this algorithm can enable farmland fertilization technology 
to be on the right track with reasonable, correct, convenient and easy fertilization. As a result, higher crop yields can be achieved, and farmland ecology contaminated by excessive application of fertilizers can be returned to normal within 5-10 years so as to produce huge economic, ecological and social benefits.

\section{Acknowledgments}

The authors are grateful for financial support from the following projects: The Natural Science Foundation of China (grant No. 41471232) and the National 973 program (grant No. 2015CB452704).

\section{Author Contributions}

Shenwu Lv and Gangcai Liu designed the research and developed the equations; Xuemei Wang contributed to data analysis and wrote the paper; all authors contributed substantially to revisions.

\section{Conflict of Interest}

The authors declare no conflict of interest.

\section{References}

1. Zhou, M.Z. Soil Fertility and Soil Testing for Fertilization; Agriculture Press: Beijing, China, 1988; pp. 332-357.

2. Tian, C.Y.; Lin, Z.A.; Zuo, Y.B. Review on several concepts on fertilizer nitrogen recovery rate and its calculation. Chin. J. Soil Sci. 2011, 42, 1530-1536. (In Chinese)

3. Sebilo, M.; Mayer, B.; Nicolardot, B.; Pinay, G.; Mariotti, A. Long-term fate of nitrate fertilizer in agricultural soils. Proc. Nat. Acad. Sci. USA 2013, 110, 18185-18189.

4. Anonym. Fertilized to death. Nature 2003, 425, 894-895.

5. Galloway, J.N.; Dentener, F.J.; Capone, D.G.; Boyer, E.W.; Howarth, R.W.; Seitzinger, S.P.; Asner, G.P.; Cleveland, C.C.; Green, P.A.; Holland, E.A.; et al. Nitrogen cycles: Past, present, and future. Biogeochemistry 2004, 70, 153-226.

6. Ju, X.T.; Pan, J.R.; Liu, X.J.; Zhang, F.S. Study on the fate of nitrogen fertilizer in winter wheat/summer maize rotation system in Beijing suburbs. Plant Nutr. Fertil. Sci. 2003, 9, 264-270.

7. Zhu, Z.L. On the methodology of recommendation for the application rate of chemical fertilizer nitrogen to crops. Plant Nutr. Fertil. Sci. 2006, 12, 1-4.

8. Cui, Z.T.; Zhang, R.L.; Sun, D.P. Analysis of inspection of several main agricultural soils' fertility in Gansu Province. Soils Fertil. 2003, 5, 3-7.

9. Gao, J.S.; Huang, J.; Dong, C.H. Effects of long-term combined application of organic and chemical fertilizers on rice yield and soil available nutrients. Acta Pedol. Sin. Chin. 2014, 51, 315-324.

10. Sun, Z.M.; Wu, Z.J.; Chen, L.J. Research advances in nitrogen fertilization and its environmental effects. Chin. J. Soil Sci. 2005, 37, 782-786.

11. Xu, Z.X. Fertilizer, Sewage and Esophageal Cancer; Science Press: Beijing, China, 2003. 
12. Melstedm, S.W. The Philosophy of Soil Testing and Plant Analysis. Part 1; Soil Science Society of America: Madison, WI, USA, 1967; pp. 13-23.

13. Rouse, R.D. Soil Test Theory and Calidration for Cotton Corn Soybeans and Coastal Bermudagrass; Agricultural Experiment Station, Auburn University: Auburn, AL, USA, 1968; pp. 58-67.

14. Lu, Y.F.; Zhou, M.Z. A study on measurement method and index of red-soil available P in arid land. Acta Pedol. Sin. 1987, 24, 325-334.

15. Yang, J.F.; Fan, D.C. A study of soil fertilizer K fertility and $\mathrm{K}$ abundance and deficiency index in Shaanxi. Sci. Agric. Sin. 1987, 20, 19-24.

16. Lu, R.K. Soil-Plant Nutrition Principle and Fertilization; Chemical Industry Press: Beijing, China, 1998; pp. 360-366.

17. Lv, S.W. A discussion of calculation equation standardization for farmland fertilization. In Chinese Association of Agricultural Science Societies; Agriculture Press: Beijing, China, 2002; pp.149-153.

18. Lv, S.W.; Zhang, Y.J. Calculation on utilization rate and requirement of phosphate and potassium fertilizer. Chin. J. Soil Sci. 2003, 34, 198-201.

19. Lv, S.W. Discussion about the fit calculating-formula of balance input N. J. China West Norm. Univ. 2004, 2591, 23-27.

20. Lv, S.W.; Tang, X.P.; Luo, M.Y.; He, H.Q. The research on surface pollution for suppressing excessive fertilization and correcting fertilization pattern. In Chinese Association of Agricultural Science Societies; Agriculture Press: Beijing, China, 2008; pp. 247-252.

21. He, D.Y.; Liao, X.L.; Zhou, W.J. A study on the conversion and efficiency of ${ }^{15} \mathrm{~N}$ green manure returned to fields after fed to pigs. Acta Pedol. Sin. 1994, 31, 277-285.

22. Shen, S.M.; Pruden, G.; Jenknson, D.S. Mineralization and immobilization of nitrogen in fumigated soil and the measurement of microbial biomass nitrogen. Soil Biol. Biochem. 1984, 16, 437-444.

23. Jenkinson, D.S.; Fox, R.H.; Rayer, J.H. Interaction between sertilizer nitrogen and soil nitrogen: The so called priming effect. J. Soil Sci. 1985, 36, 425-434.

24. Shen, S.M.; Hart, B.S.; Powlson, D.S. The nitrogen cycle in the Broadbalk when experiment: ${ }^{15} \mathrm{~N}$-labelled fertilizer residues in the soil and in the soil microbial biomass. Soil Biol. Biochem. 1989, 21, 529-533.

25. Jensen, L.S.; Schjoerring, J.K.; van der Hoek, K.W.; Poulsen, H.D.; Zevenbergen, J.F.; Pallière, C.; Brentrup, F.; Jongbloed, A.W.; Willems, J.; van Grinsven, H. Benefits of Nitrogen for Food Fiber and Industrial Production; The European Nitrogen Assessment: Cambridge, UK, 2011; pp. 32-61.

26. Lv, S.W.; Li, J.L. Impacts of rainfall and soil humidity on soil erosion. Acta Pedol. Sin. 1992, 29, 92-101.

(C) 2015 by the authors; licensee MDPI, Basel, Switzerland. This article is an open access article distributed under the terms and conditions of the Creative Commons Attribution license (http://creativecommons.org/licenses/by/4.0/). 